\title{
Effect of Nursing Care Protocol on Nurses' Performance to Prevent Drug Extravasation among Children Undergoing Chemotherapy
}

\author{
Nermeen Atya Abd Elfatah ${ }^{1}$, Nagwa Ahmed Zein Aldein ${ }^{2}$, Khadiga Mohammed Said ${ }^{3}$ and \\ Hanan Nabwy EL-aasar ${ }^{4}$
}

(1) Teaching Specialist of Technical Health Institute of Imbaba, Egypt, (2) Professor of Pediatric Nursing-El-Menoufia University, Egypt and (3,4) Assistant Professor of Pediatric Nursing, Benha University, Egypt

\begin{abstract}
Background: Extravasation of chemotherapy is leakage of chemotherapy drugs into the subcutaneous tissues surrounding the administration site. Aim of the study: This study aimed to assess the effect of nursing care protocol on nurses' performance during drug extravasation among children. Research Design: A quasi experimental design (pre and posttest) was used to achieve the aim of the study. Setting: The study was conducted at the Pediatric Oncology Unit in Specialized Pediatric Hospital at Benha City. Subjects: a- A convenient sample of all available nurses $(n=30)$ who working in the previously mentioned study setting was included during period of data collection. b- A purposive sample of available children $(n=50)$. Tools of data collection: Three tools utilized for collection data. I: A Structured Interviewing sheet, II: Chemotherapy Administration Observational Checklists to assess nurses' practices before, during and after administration of chemotherapeutic agents for children, and III: Infiltration and extravasation scale to assess signs of infiltration and extravasation of chemotherapeutic agents. Results: There were statistically significant differences in improvement nurses' knowledge and practice regarding nursing care protocol before and after program and after three months. Conclusion: There was a significant improvement on nursing staff knowledge, performance regarding to administration of intravenous chemotherapeutic agents, prevention and management of chemotherapy extravasation and significant reduction in extravasation occurrence in studied children. Recommendation: All nurses who administer chemotherapeutic agents should complete regular periodic in services training programs to keep them up to date regarding to safe and efficient administration of chemotherapeutic agents.
\end{abstract}

Key words: Chemotherapy, Children, Extravasation, Drug, Nursing Care Protocol, Performance

\section{Introduction}

Chemotherapy is treatment that uses drugs to stop the growth of cancer cells, either by killing the cells or by stopping them from dividing. Chemotherapy may be given by mouth, injection, or infusion, or on the skin, depending on the type and stage of the cancer being treated. It may be given alone or with other treatments, such as surgery, radiation therapy, or biologic therapy (Oncology Nursing Society, 2015).
Extravasation is the process by which any liquid (fluid or drug) accidentally leaks into the surrounding tissue. In terms of cancer therapy, extravasation refers to the inadvertent infiltration of chemotherapy into the subcutaneous or subdermal tissues surrounding the intravenous or intra-arterial administration site. Extravasated drugs are classified according to their potential for causing damage as 'vesicant', 'irritant' and 'nonvesicant'. Some vesicant drugs are 
further classified into two groups: DNA binding and non-DNA binding. The drugs are divided into vesicants, exfoliants, irritants, inflammitants and neutrals (Luke, 2015).

Children with cancer are at risk for extravasation because these often children require multiple IntraVenous (IV) infusions, have malnourishment, need frequent administration of drugs via the IV route as well as other treatment related side effects which may cause their veins to be thin, fragile and reduce the number of safe intravenous sites (Hadaway, 2016).

\section{Significance of the study}

Chemotherapy extravasation can be a serious complication of a serious curative therapies and ischemic nerve damage can occur within 24 hours, causing serious functional loss of the affected extremity. Risk factors of chemotherapy extravasation can be related to poor technique and inexperience, a poorly secured needle, or children variables such as poor nutritional status, fragility of skin and connective tissue as a result of disease or therapy and sclerosed veins. (Hadaway, 2016).

So, early detection of chemotherapy infiltration or extravasation by nurses may prevent nerve damage and tissue sloughing, which could require surgery. Consequently, chemotherapy extravasation must be early identified and successfully treated to avoid serious negative consequences. As well as the nurses administering chemotherapeutic agents should be aware of early signs of chemotherapy extravasation to prevent and manage the complications of extravasation.

\section{Aim of the study}

The aim of the study was to assess the effect of nursing care protocol on nurses' performance during drug extravasation among children.

\section{Research Hypotheses}

1-Nursing care protocol would expect to improve nurses' knowledge and practices regarding prevention of chemotherapy drug extravasation.

2-Nursing care protocol would expect to reduce the occurrence of drug extravasation for children undergoing chemotherapy.

\section{Subjects and Method \\ Research Design:}

A quasi experimental research design (pre and posttest) was utilized to conduct this study.

\section{Setting:}

The study was conducted at the Pediatric Oncology Unit of Specialized Pediatric Hospital at Benha City affiliated to Ministry of Health and Population. It consists of three rooms for children having different diagnosis. Every room contained 4 beds and the third room special for isolation contained one bed.

\section{Sample:}

a- Convenience sampling of all available nurses $(n=30)$ who working in the previously mentioned study setting was included during period of data collection.

b-A purposive sample of available children $(n=50)$ under the following inclusion criteria:

-Male and female children aged from 1year to 16 years receiving chemotherapy drug.

-Free from any skin problems in upper extremities.

-No shunt in upper extremities.

\section{Tools of data collection:-}

Data of the current study was collected through using the following three tools:

\section{Tool I: A Structured Interviewing Questionnaire}

It was prepared by the researcher under thesis supervisors after reviewing related 


\section{Effect of Nursing Care Protocol on Nurses' Performance to Prevent Drug \\ Extravasation among Children Undergoing Chemotherapy}

literature, text books, articles and magazines. It was consists of two parts:

\section{Part 1:}

a- Personal characteristics of the studied nurses: such as age, gender, qualification, years of experience and attendance of training courses related extravasation. It contained of 5 questions).

b- Personal characteristics of the child such as: (age, gender, ranking, education and Childs' diagnosis. It contained of six questions).

\section{Part 2:}

a- Nurses' knowledge about chemotherapy administration. It contained eight questions.

b- Nurses' knowledge about chemotherapy extravasation. It contained six questions.

\section{Scoring system:}

Scoring system for knowledge designed as following; giving a score of two for complete correct answers, giving a score of one for the incomplete correct answers and zero for the wrong answer and didn't know. The total score level of knowledge were ranged according to

- Score $<50 \%$ referred to poor level of knowledge.

- Score from $50<75 \%$ referred to average level of knowledge.

- Score from $75 \leq 100$ referred to good level of knowledge.

Tool II: Chemotherapy Administration Observational Checklists: It was adopted from Kline, (2012), it was used to assess nurses practices before, during and after administration of chemotherapeutic agents for children. It contained of seven questions.

\section{Scoring system:}

The scoring system for nurses' practice designed as following; giving a Score (2) was given for each correct step, (1) for incompletely done and (0) for incorrectly done or incorrect practice.

The total level of practice was calculated according to

- Score $<80 \%$ referred to incompetent level of practice.

- Score $\geq 80 \%$ referred to competent level of practice.

\section{Tool III: Infiltration and Extravasation} Scale: It was adopted from Infusion Nurses' Society, (2011), it was used to assess signs of infiltration and extravasation of chemotherapeutic agents. It contained seven items. This scale includes parameters namely: skin color, integrity, temperature, edema, mobility, pain and fever. It will assessed by using a five likert scale ranged from normal (zero) to worst (4 point) except for pain scale ranged from $0-10$ as indicated from no pain to worst or sever pain.

\section{Scoring system:}

Total score of scale:

- Score $24-28 \geq(80 \%)$ considered efficiently done.

- Score $23<(80 \%)$ considered un efficiently done.

\section{Content validity:}

Data collection tools was submitted to a jury of 3 experts to be asked for review the tools of data collection. Their comments were taken into consideration.

\section{Reliability:}

Reliability of the tools was done by using Cronbach alpha coefficient test which revealed that each of three tools consisted of relatively homogenous items as indicated by high reliability for each tool. The internal consistency of the tools was as the following: 


\begin{tabular}{|l|l|}
\hline Tools & Cronbach's alpha \\
\hline $\begin{array}{l}\text { Structured interviewing } \\
\text { questionnaire }\end{array}$ & 0.89 \\
\hline Observational checklist & 0.92 \\
\hline Extravasation scale & 0.90 \\
\hline
\end{tabular}

\section{Ethical considerations:}

- An official permission was obtained from the director of Specialized Pediatric Hospital at Benha City.

- Oral informed consent was obtained from the studied nurses, parents and their children.

- Aim of the study, purposes and expected out comes was explained for each study subjects.

- The participants were assured that the obtained information throughout the study was treated confidentiality.

- Each study subjects have the right to withdraw at any time during the data collection without explanation of any rationales.

\section{Pilot study:}

The pilot study was conducted on $10 \%$ (3) of the subject to evaluate the clarity, applicability, efficiency time needed for each data collection tool. This sample is included in this study. Results of the pilot study were help in necessary modification of the data collection tools.

\section{Field work:}

\section{Assessment phase}

The process of data collection carried out from the beginning of February 2020 to middle of march 2020. The researcher visited the Pediatric Oncology Unit in Specialized Pediatric Hospital at Benha City, Data was collected three days weekly in the morning and afternoon shifting, the researcher introduced herself with available nurses in oncology unit and explained the aim of the study and take their oral approval to participate in the study prior data collection, then the researcher assessed nurses' performance regarding their care of extravasation of chemotherapy.

\section{Program implementation:}

The questionnaire sheets were administered by the researcher to all nurses to assess their knowledge and performance about care of children with chemotherapy extravasation. The average time needed for completion of questionnaire sheets by nurses was between 20- 30 minutes.

\section{Program construction:}

The educational program for nurses was designed by the researcher according to the nurses' needs regarding care of children with chemotherapy extravasation. It was constructed, revised and modified from the related literature to improve the nurses' knowledge and practices regarding chemotherapy administration and extravasation with children. The contents were prepared according to nurses level of understanding in simple, organized and scientific Arabic language.

\section{Statement of objective:}

The general objectives of the program were to improve nurses' knowledge and practice about chemotherapy administration and extravasation.

\section{Specific objectives:}

- Describe definition of chemotherapy.

-Mention types of chemotherapeutic agents.

- Identify action of chemotherapy.

- Describe preparation of chemotherapeutic

- Discuss routs of administration.

-Identify precautions during and after administration of chemotherapy.

-Enumerate side effects of chemotherapy.

- Define chemotherapeutic extravasation.

-Know causes of chemotherapeutic extravasation. 


\section{Effect of Nursing Care Protocol on Nurses' Performance to Prevent Drug Extravasation among Children Undergoing Chemotherapy}

-List clinical signs and symptoms of extravasation

-Identify complications of chemotherapeutic extravasation.

- Apply measures of prevention chemotherapy extravasation.

-List the contents of extravasation kit.

- Apply general procedures for management of extravasation cases.

-Identify documentation of chemotherapy and chemotherapy extravasation.

- Know grades of chemotherapy extravasation.

\section{Implementation of the program:}

The implementation of the program phase was achieved (7) sessions at a period, each session started by a summary of the previous session and objectives of the new one. Taking into consideration, the use of Arabic language that suit the nurses educational level. Motivation and reinforcement during session were used to enhance motivation for the sharing this study.

The researcher was available at the previous mentioned three days per week at the previous mentioned three days per week at previous setting. The studied nurses were divided into 6 groups and each group was consisted of 5 nurses. Each nurse was supplemented with booklet and the researcher continued to reinforce the gained information, answered any raised questions and gave feedback.

Different teaching strategies were designed lecture, group discussion, demonstration and remonstration; brain storming, teaching media utilized were handouts, visual materials. Data was collected from the beginning of february2020 to end of December 2020.

\section{Evaluation phase:}

After the implementation of the program contents. The post tests were administered to assess nurses' knowledge and practice using the same format pretest. This helped to evaluate the effect of implemented program. This was done after intervention.

\section{Statistical analysis:}

Statistical analysis was done by using Statistical Package for Social Sciences (SPSS) version 20. Data were collected, revised, coded, organized, tabulated, and analyzed using frequencies, number, percentage, mean scores, standard deviation and correlation coefficient. Data were presented in the form of tables and figures. Quantitative data was presented by mean (x) and standard deviation (SD). Qualitative data was presented in the form of frequency distribution tables, number and percent. It was analyzed by Chi- Square test (x2) \& correlation to detect the relation between the variables of the study (P-value). Statistical significance was considered as follows:

-P- value >0.05 Not Significant

-P-value < 0.05 Significant

$\bullet$ P- value < 0.001 Highly Significant

\section{Results}

Table (1): Shows that, $36.7 \%$ of the studied nurses aged between 30 to less than 40 years old with mean and standard deviation of $32.83 \pm 8.65,100.0 \%$ were females, and $40.0 \%$ had nursing diploma. As regards years of experience, $36.7 \%$ of them had from 10 to less than 15 years of experience with mean and standard deviation of $12.23 \pm 5.56$, and $53.3 \%$ of them didn't attend any training courses related extravasation.

Table (2): Describes that $44.0 \%$ of the studied children aged between 10 to 16 years old with mean and standard deviation of $9.17 \pm 4.71$, $54.0 \%$ of them were males, $40.0 \%$ were the second child, and $44.0 \%$ of them were in preparatory school. As regards diagnosis, 
$38.0 \%$ of them had leukemia, and $64.0 \%$ of them had no family history of cancer.

Figure (1): Demonstrates that, $56.7 \%$ of the studied nurses had good total knowledge score regarding chemotherapy administration and extravasation before the implementation (pretest) of the protocol of care, which increased to $80.0 \%$ immediately after implementation (posttest) of the protocol of care then decreased to $73.3 \%$ at the follow up phase.

Figure (2): Denotes that $73.3 \%$ of the studied nurses had competent total practices score regarding administration of chemotherapeutic agents for children before the implementation (pretest) of the protocol of care, which increased to $90.0 \%$ immediately after implementation (posttest) of the protocol of care then decreased to $83.3 \%$ at the follow up phase.

Table (3): Illustrates that, $58.0 \%$ of the studied nurses efficiently reduce the occurrence of drug extravasation for children undergoing chemotherapy prior the implementation (pretest) of the protocol of care, which improved to $80.0 \%$ immediately after implementation (posttest) of the protocol of care, then decline to $76.0 \%$ at the follow up phase. This table also shows that there were highly statistically significant differences in all items related to the studied nurses' practices to reduce the occurrence of drug extravasation for children undergoing chemotherapy in pretest, posttest, and follow up phase $(\mathrm{P}<0.001)$.

Table (4): Indicates that, there were highly statistically significant positive correlations between the studied nurses' total knowledge and total practices score in pretest, posttest, and follow up phase $(\mathrm{P}<0.001)$.

Table (1): Percentage distribution of the studied nurses according to their personal characteristics, $(n=30)$.

\begin{tabular}{|c|c|c|}
\hline Personal characteristics & $\overline{\text { No. }}$ & $\%$ \\
\hline \multicolumn{3}{|l|}{ Age (Years): } \\
\hline Less than 20 years & 4 & 13.3 \\
\hline - $20->30$ & 6 & 20.0 \\
\hline - $30->40$ & 11 & 36.7 \\
\hline - $40+$ & 9 & 30.0 \\
\hline \multicolumn{3}{|c|}{$\overline{\mathrm{X}} \pm \mathrm{SD} \quad 32.83 \pm 8.65$} \\
\hline \multicolumn{3}{|l|}{ Gender: } \\
\hline - Male & 0 & 0.0 \\
\hline - Female & 30 & 100.0 \\
\hline \multicolumn{3}{|l|}{ Qualification: } \\
\hline - Nursing diploma & 12 & 40.0 \\
\hline - Nursing institute & 8 & 26.7 \\
\hline - $\quad$ Bachelor of nursing & 7 & 23.3 \\
\hline - $\quad$ Postgraduate studies & 3 & 10.0 \\
\hline \multicolumn{3}{|l|}{ Years of experience: } \\
\hline - Less than one year & 0 & 0.0 \\
\hline - $1->5$ & 4 & 13.3 \\
\hline - $5->10$ & 6 & 20.0 \\
\hline - $\quad 10->15$ & 11 & 36.7 \\
\hline - $15+$ & 9 & 30.0 \\
\hline \multicolumn{3}{|c|}{$\bar{X} \pm$ SD $12.23 \pm 5.56$} \\
\hline \multicolumn{3}{|c|}{ Attendance of training courses related extravasation: } \\
\hline - Yes & 14 & 46.7 \\
\hline - No & 16 & 53.3 \\
\hline
\end{tabular}




\section{Effect of Nursing Care Protocol on Nurses' Performance to Prevent Drug Extravasation among Children Undergoing Chemotherapy}

Table (2): Percentage distribution of the studied children according to their personal characteristics, $(\mathbf{n}=\mathbf{5 0})$.

\begin{tabular}{|c|c|c|}
\hline Personal characteristics & No. & $\%$ \\
\hline \multicolumn{3}{|l|}{ Age (Years): } \\
\hline$\cdot 1->5$ & 13 & 26.0 \\
\hline $.5->10$ & 15 & 30.0 \\
\hline$\cdot 10-16$ & 22 & 44.0 \\
\hline \multicolumn{3}{|l|}{$\bar{X} \pm \mathrm{SD} \quad 9.17 \pm 4.71$} \\
\hline \multicolumn{3}{|l|}{ Gender: } \\
\hline - Male & 27 & 54.0 \\
\hline - Female & 23 & 46.0 \\
\hline \multicolumn{3}{|l|}{ Ranking: } \\
\hline - First & 10 & 20.0 \\
\hline - Second & 20 & 40.0 \\
\hline - Third & 9 & 18.0 \\
\hline -Fourth and more & 11 & 22.0 \\
\hline \multicolumn{3}{|l|}{ Educational level: } \\
\hline - Before school age & 13 & 26.0 \\
\hline - Primary school & 15 & 30.0 \\
\hline - Preparatory school & 22 & 44.0 \\
\hline \multicolumn{3}{|l|}{$\overline{\text { Diagnosis: }}$} \\
\hline -Leukemia & 19 & 38.0 \\
\hline -Lymphoma & 15 & 30.0 \\
\hline -Wilms tumor & 16 & 32.0 \\
\hline - Others & 0 & 0.0 \\
\hline \multicolumn{3}{|l|}{ Presence of family history of cancer: } \\
\hline - Yes & 18 & 36.0 \\
\hline - No & 32 & 64.0 \\
\hline
\end{tabular}

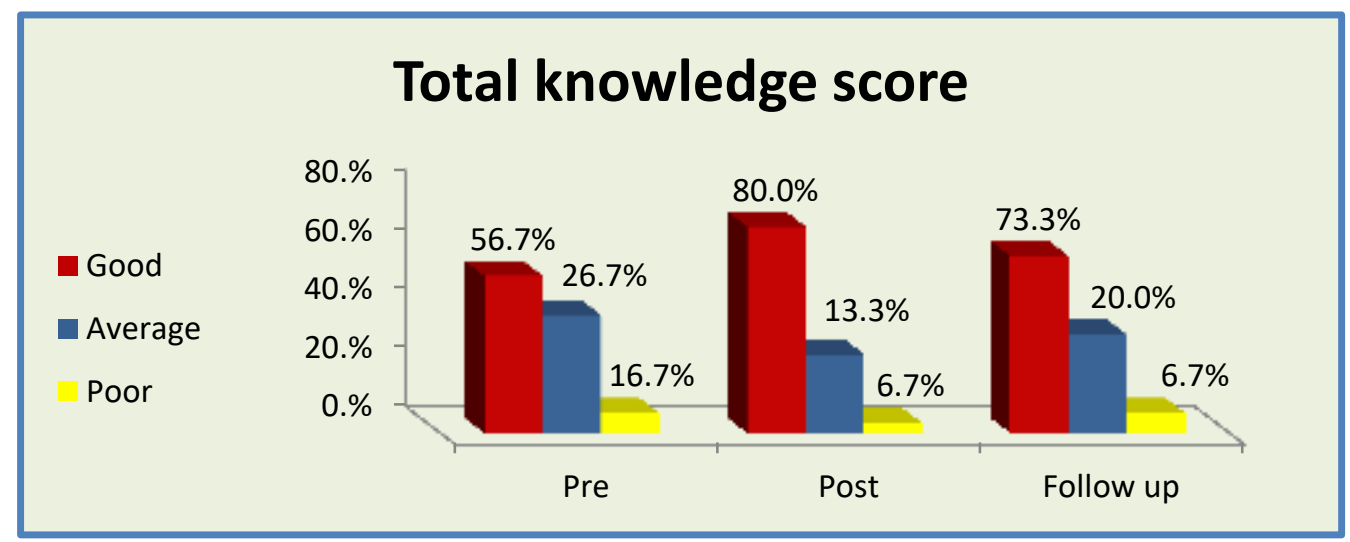

Figure (1): Percentage distribution of the studied nurses' total knowledge score regarding chemotherapy administration and extravasation in pretest, posttest, and follow up phase, $(\mathrm{n}=$ 30). 
Nermeen Atya, Nagwa Ahmed, Kadiga mohammed and Hanan Nabwy

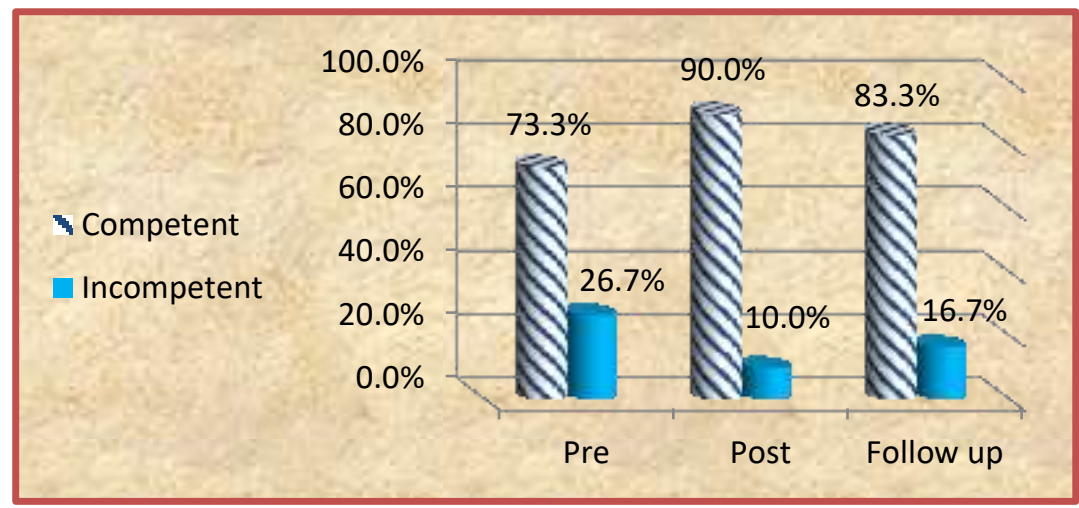

Figure (2): Percentage distribution of the studied nurses' total practices score regarding administration of chemotherapeutic agents for children in pretest, posttest, and follow up phase, $(\mathbf{n}=30)$.

Table (3): Signs of infiltration and extravasation of chemotherapeutic agents. Percentage distribution between signs of infiltration and extravasation of chemotherapeutic agents in pretest, posttest, and follow up phase, $(n=50)$.

\begin{tabular}{|c|c|c|c|c|c|c|c|c|}
\hline \multirow{2}{*}{$\begin{array}{l}\text { Signs of infiltration and } \\
\text { Extravasation }\end{array}$} & \multicolumn{2}{|c|}{$\overline{\text { Pretest }}$} & \multicolumn{2}{|c|}{$\overline{\text { Posttest }}$} & \multicolumn{2}{|c|}{ Follow up } & \multicolumn{2}{|c|}{ Significance test } \\
\hline & No. & $\%$ & No. & $\%$ & No. & $\%$ & $\chi^{2}$ & P-value \\
\hline \multicolumn{9}{|l|}{ Skin color: } \\
\hline - Normal & 20 & 40.0 & 35 & 70.0 & 33 & 66.0 & \multirow{5}{*}{15.55} & \multirow{5}{*}{$0.001 *$} \\
\hline - Pink & 11 & 22.0 & 6 & 12.0 & 7 & 14.0 & & \\
\hline - Red & 10 & 20.0 & 5 & 10.0 & 6 & 12.0 & & \\
\hline - Blanched area surrounded by red & 6 & 12.0 & 2 & 4.0 & 3 & 6.0 & & \\
\hline - Blackened & 3 & 6.0 & 2 & 4.0 & 1 & 2.0 & & \\
\hline \multicolumn{9}{|l|}{ Skin integrity: } \\
\hline - Un broken & 20 & 40.0 & 38 & 76.0 & 36 & 72.0 & \multirow{5}{*}{17.43} & \multirow{5}{*}{$0.001 *$} \\
\hline - Blistered & 19 & 38.0 & 8 & 16.0 & 9 & 18.0 & & \\
\hline - Superficial skin loss & 10 & 20.0 & 4 & 8.0 & 5 & 10.0 & & \\
\hline $\begin{array}{l}\text { Tissue loss \& exposed } \\
\text { subcutaneous tissue }\end{array}$ & 1 & 2.0 & 0 & 0.0 & 0.0 & 0.0 & & \\
\hline $\begin{array}{l}\text { Tissue loss \& exposed } \\
\text { bone/muscle with necrosis carter }\end{array}$ & 0 & 0.0 & 0 & 0.0 & 0.0 & 0.0 & & \\
\hline \multicolumn{9}{|l|}{ Skin temperature: } \\
\hline - Normal & 25 & 50.0 & 40 & 80.0 & 38 & 76.0 & \multirow{3}{*}{14.22} & \multirow{3}{*}{$0.001 *$} \\
\hline - Warm & 15 & 30.0 & 8 & 16.0 & 8 & 16.0 & & \\
\hline - Hot & 10 & 20.0 & 2 & 4.0 & 4 & 8.0 & & \\
\hline \multicolumn{9}{|l|}{ Edema: } \\
\hline - Absent & 26 & 52.0 & 42 & 84.0 & 36 & 72.0 & \multirow{3}{*}{18.08} & \multirow{3}{*}{$0.001 *$} \\
\hline - Non pitting & 14 & 28.0 & 5 & 10.0 & 9 & 18.0 & & \\
\hline - Pitting & 10 & 20.0 & 3 & 6.0 & 5 & 10.0 & & \\
\hline \multicolumn{9}{|l|}{ Mobility: } \\
\hline - Full & 30 & 60.0 & 38 & 76.0 & 35 & 70.0 & \multirow{4}{*}{16.08} & \multirow{4}{*}{$0.001 *$} \\
\hline - Slightly limited & 9 & 18.0 & 4 & 8.0 & 7 & 14.0 & & \\
\hline - Very limited & 5 & 10.0 & 4 & 8.0 & 5 & 10.0 & & \\
\hline - Immobile & 6 & 12.0 & 4 & 8.0 & 3 & 8.0 & & \\
\hline \multicolumn{9}{|l|}{ Pain: } \\
\hline - No pain & 30 & 60.0 & 43 & 86.0 & 40 & 80.0 & \multirow{4}{*}{20.31} & \multirow{4}{*}{$0.001 *$} \\
\hline - Mild pain & 10 & 20.0 & 4 & 8.0 & 5 & 10.0 & & \\
\hline - Moderate pain & 7 & 14.0 & 2 & 4.0 & 3 & 8.0 & & \\
\hline - Worst pain & 3 & 6.0 & 1 & 2.0 & 2 & 4.0 & & \\
\hline \multicolumn{9}{|l|}{ Fever: } \\
\hline - Normal & 30 & 60.0 & 44 & 88.0 & 40 & 80.0 & \multirow[b]{2}{*}{19.45} & \multirow[b]{2}{*}{$0.001 *$} \\
\hline - Elevated & 20 & 40.0 & 6 & 12.0 & 10 & 20.0 & & \\
\hline Total & & & & & & & & \\
\hline Efficiently done & 29 & 58.0 & 40 & 80.0 & 38 & 76.0 & & \\
\hline Un efficiently done & 21 & 42.0 & 10 & 20.0 & 12 & 24.0 & 23.38 & $0.001 *$ \\
\hline
\end{tabular}

*Statistically significant at $\mathrm{p}<0.05$

** Highly statistically significant at $\mathrm{p}<0.001$ 


\section{Effect of Nursing Care Protocol on Nurses' Performance to Prevent Drug \\ Extravasation among Children Undergoing Chemotherapy}

Table (4): Correlation between the studied nurses' total knowledge and total practices score in pretest, posttest, and follow up phase, $(n=30)$.

\begin{tabular}{|c|c|c|c|c|c|c|c|}
\hline \multirow{3}{*}{\multicolumn{2}{|c|}{ Variables }} & \multicolumn{6}{|c|}{ Total knowledge core } \\
\hline & & \multicolumn{2}{|c|}{ Pretest } & \multicolumn{2}{|c|}{ Posttest } & \multicolumn{2}{|c|}{ Follow up } \\
\hline & & & $\mathrm{P}$-value & $\mathrm{R}$ & P-value & $\mathrm{r}$ & P-value \\
\hline \multirow[t]{3}{*}{ Total practices score } & $\overline{\text { Pretest }}$ & 0.560 & $\overline{0.001 * *}$ & & & & \\
\hline & Posttest & & & 0.729 & $0.001 * *$ & & \\
\hline & Follow up & & & & & 0.670 & $0.001 * *$ \\
\hline
\end{tabular}

**Correlation is highly significant at the 0.001 level.

\section{Discussion}

Regarding bio-socio-demographic characteristics, the characteristics of the studied sample revealed that, about more than one third of the studied nurses aged between 30 to less than 40 years old with mean and standard deviation of $32.83 \pm 8.65$, this result agrees with Goolsby and Lombardo, (2016) who studied" Extravasation of chemotherapeutic agents: prevention and treatment" and reported that, more than one third of the total studied nurses were in the age group from 35 - 45 years old.

Concerning sex, the present study showed that all of the studied nurses were females, this result agrees with Mohamed, (2015) who studied" The effect of designed nursing protocol on nurse's knowledge and practice regarding chemotherapy" and reported that approximately half of studied nurses were female

As regard level of education the present study finding showed that two fifth of them had nursing diploma. These results were consistent with of Nasser, (2014) who found in similar study about "Assessment of nurses caring for patients with cancer undergoing chemotherapy" and showed that most of the nurses had nursing school diploma. From the point view of the researcher these results could be linked to the fact that, nursing diploma provide the hospitals with large number of graduated diploma nurses than other agencies such as faculties of nursing and technical nursing institute and it is known that most graduates of the collage of Nursing and medical institutes from women.

Concerning the studied nurses' knowledge as regards chemotherapy administration and extravasation. The current study findings revealed that the level of knowledge for more than half of nurses before the implementation of the protocol of care was poor. From the researcher point of view this result may be attributed to one or more of the following reasons; inadequate courses related to oncology nursing in undergraduate curriculum study, improper preparation and orientation for the nurses working with such group of patients and also lack of continuous education for nurses. These finding were agree with Mohamed, (2016) who studied in similar study "Assessment of nursing guidelines given to children with cancer undergoing chemotherapy" and proved that more than two thirds of nurses had poor knowledge of cancer and chemotherapy. 
On the contrary immediately after implementation of the protocol of care the total knowledge scores of the studied nurses were good. From the point view of the researcher, the program was a successful method to increase knowledge, nurses become aware about dangerous of chemotherapy extravasation and importance to refresh their knowledge, beside adequate supervision from well qualified supervisor nurses in chemotherapy administration, availability of the teacher in the field for more qualification, using simple language and frequent repetition to fix the knowledge. This finding was in the same line with Mohamed, (2015) who studied" Effect of designed nursing protocol on nurse's knowledge and practice regarding chemotherapy" and mentioned that the implementation of the designed protocol showed an improvement in the nurses' level of knowledge regarding the care offered to patient during administering chemotherapy.

Concerning, follow up phase, this percentage of nurses was decreased to less than three quarter. The researcher believed that the improvement in knowledge was lost one month after implementation of protocol of care. This result might be explained by the fact that, knowledge retention is usually affected by time.

Concerning nurses' levels of practice related to chemotherapy administration, the study revealed that more than half of the studied nurses had correct total practices regarding administration of chemotherapeutic agents for children before the implementation of program comparing to post and follow up phase was poor. From the researcher point of view this may be attributed to the nurses neglected essential steps, or perform them incompletely during chemotherapeutic agent's administration; the nurses were not following the international standards for chemotherapy preparation and administration. This finding was in line with Ritchie et al., (2018) who studied" Exposure risk in the handling and administration of chemotherapy Agents and found that chemotherapy preparation and administration was not according to international standards, and recommends that chemotherapy should be prepared by trained pharmacist and administered only by trained nursing staff.

Conversely, immediately and follow up phase after the implementation of protocol of care, there was improvement to nurses' practices related to chemotherapeutic agents administration. From the researcher point view, the nurses became had adequate knowledge about the right methods for administration of chemotherapeutic agents and available booklets containing basic knowledge and principles as regards chemotherapy administration, its side effects and how to manage it, potential complications of administering chemotherapy, as well as they were skilled at performing immediate intervention.

The present study was in harmony with Rudolph and Larson, (2018) who studied" Etiology and treatment of chemotherapeutic agent extravasation injuries" and found that there was a great improvement in the practice score levels obtained by nurses after the application of the designed nursing protocol. Concerning to measures of nurses in the event of extravasation. Small number of the nurses used prevention and management of extravasation compared to post and follow up test. This finding was in harmony with a, Abd-ELgaffar, (2015) who studied "Evaluation of handling practices of oncology nurses during chemotherapy Preparation and Administration in oncology hospital" and mentioned that none of nurses had good level on management of extravasation before the program implementation. Additionally, this 


\section{Effect of Nursing Care Protocol on Nurses' Performance to Prevent Drug \\ Extravasation among Children Undergoing Chemotherapy}

result was in agreement with finding of Hassan, (2016) who studied "Evaluation of nursing care protocol given to children with cancer undergoing chemotherapy and revealed that more than three fourths of nurses had poor level of knowledge regarding to extravasation and its management

Conversely, comparing to post and follow up test, there was improvement of nurses manage chemotherapy extravasation. From the researcher' point of view, nurses become aware about dangerous of chemotherapy extravasation and importance to refresh their knowledge, beside adequate supervision from well qualified supervisor nurses in chemotherapy administration. This result was in the same line with Ignoffo and Friedman (2017) who studied "Therapy of local toxicities caused by extravasation of cancer chemotherapeutic drugs" and mentioned that, persons responsible for administrating cytotoxic drugs should be informed and educated about the drugs and the problems they may cause in the case of extravasation and the procedures to follow if this happens. In relation to follow up test, findings of the current study illustrated that the nurses' knowledge and practices slightly decreased than posttest. This drop in follow up test could be explained by the fact that there is no continuous stress on the importance of training courses to ensure safe and effective administration of chemotherapy. Also Aly et al., (2016) supported the previous results and reported that more frequent training was required. Also, he noted that skills are decreased in 1 to 2 weeks after training.

\section{Conclusion}

The research hypotheses are accepted and the protocol of care was effective. Additionally there was a significant improvement on nursing staff knowledge, practices regarding administration of intravenous chemotherapeutic agents, prevention and management of chemotherapy extravasation.

\section{Recommendations}

-Written guidelines for handling cytotoxic agents and management procedures in case of extravasation should be available in all health care settings where chemotherapeutic agents are administered and the children should be closely monitored for potential extravasation, so that appropriate action can be taken early.

-It is essential that all nurses who administer chemotherapeutic agents should complete regular periodic in services training programs to keep them up to date regarding to safe and efficient administration of chemotherapeutic agents.

-Careful nursing assessment for children before, during and after chemotherapy administration is a crucial component toward preventing chemotherapy extravasation.

-An extravasation tray should be kept in each children care area where chemotherapy is administered and must check its contents periodically.

\section{References}

Abd-ELgaffar, S. (2015). Evaluation Practices of Oncology Nurses during Chemotherapy Preparation and Administration in Menoufia Oncology Hospital International Journal of Novel.

Aly, H., Attia, A \& Abd El Rahman, S. (2016). Retention of Cardio Pulmonary Resuscitation Skills and Knowledge by Nursing Students: The Effect of Two Teaching Methods. IX International Medical Congress. Faculty of Medicine for Girls, Al- Azhar University, Cairo- Egypt.

Goolsby, T and Lombardo, F. (2016). Extravasation of chemotherapeutic agents: Prevention and Treatment. Semin Oncol.; 33(1):139-143. 


\section{Nermeen Atya, Nagwa Ahmed, Kadiga mohammed and Hanan Nabwy}

Hadaway, L. (2016). Infiltration and Extravasation, Preventing a complication of IV catherterization, American Journal of Nursing, 107 (8), p64 - 72.

Hassan, M. (2016). Evaluation of Nursing Care Protocol Given to Children with Cancer undergoing Chemotherapy, Master Thesis, Pediatric Nursing Depatment, Faculty of Nursing. Ain Shams University.

Ignoffo, R and Friedman, M. (2017). Therapy of Local Toxicities caused by Extravasation of Cancer Chemotherapeutic Drugs. Cancer Treat Rev.; 7 (1):17-27.

Infusion Nurses' Society, (2011). Infusion Nursing Standards of Practice, Journal of Intravenous Nursing. 23(65).

Kline, E. (2012). The Pediatric Chemotherapy and Biotherapy Curriculum, Association of Pediatric Oncology Nurses, United State of America. pp. 139-142.

Luke, E. (2015). Mitoxantrone-Induced Extravasation. Oncol Nurs Forum.; 32(1):2729.

Mohamed, H. (2016). Assessment of Nursing Guidelines given to Children with Cancer undergoing Chemotherapy, Master Thesis,
Pediatric Nursing Depatment, Faculty of Nursing. Ain Shams University

Mohamed, N. (2015). Effect of Designed Nursing Protocol on Nurse's Knowledge and Practice regarding Chemotherapy, Master Thesis, Medical surgical Nursing Department, Faculty of Nursing Assiut University.

Nasser, M. (2014). Assessment of Nurses Caring for Cancer Patient under Chemotherapy, Master Thesis, Faculty of Nursing, Ain Shams University.

Oncology Nursing Society, (2015). Cancer Chemotherapy Guidelines: Recommendations for the Management of Extravasation, Hypersensitivity and Anaphylaxis, Oncology Nursing Press, Philadelphia

Ritchie, M., McAdams, C and Fritz, N. (2018). Exposure Risk in the Handling and Administration of Chemotherapy Agents: A Review and Synthesis of the Literature. The Online Journal of Knowledge Synthesis for Nursing, 7 (4).

Rudolph, R and Larson, D. (2018). Etiology and Treatment of Chemotherapeutic Agent Extravasation Injuries: A review. J Clin Oncol.; 7(5):1116-1126 
تأثير برتكول الرعاية التمريضية على أداء الممرضات لمنع التسرب الوريدى بين الأطفال الذين يخضعون للعلاج الكيماوى

نرمين عطية عبد الفتاح عطيه ـ نجوى احمد زين الدين ـ خديجة محمد سعيد- حنان نبوى الاعصر

التسرب الوريدى للعلاج الكيماوى هو تسرب غير مقصود لأدوية العلاج الكيماوى من الوريد الى

الأنسجة المحيطة به. لذلك هدفت الدر اسة الى تحديد تأثثر برتكول الرعاية التمريضية على أداء الممرضات لمنع

التسرب الوريدى بين الأطفال الذين يخضعون للعلاج الكيماوى .وقد اجريت هذه الدراسة فى قسم الأورام بمستشفى الأطفال التخصصى بمدينة بنها على الممرضات المتاحين الذين يعملون فى وحدة أورام الأطفال و عددهم • ب ممرضه.و عدد الاطفال المتاحين(• ). حيث كثفت النتائج عن أن البرنامج التعليمى كان فعال فى تحسين معلومات وممارسات الممرضات فيما بتعلق بإعطاء عو امل العلاج الكيميائي للأطفال .و أوصت النتائج بان تتوفر لاى التمريض مر اكز تدريب منتظمة للتمريض لكى تساعدهم على فهم البر امج. 